\title{
Water Scarcity: Fact or Fiction?
}

\author{
Xiaomeng $\mathrm{Yu}^{1, \text { a }}$ \\ ${ }^{1}$ School of the North China Electric Power University, Baoding 071000, China; \\ a1147821514@qq.com
}

Keywords: Water Supply and Demand Indicator system (WSDI) Supply Index (SI) Demand Index (DI) Autoregressive Integrated Moving Average (ARIMA)

\begin{abstract}
In this paper, first we set up a Water Supply and Demand Indicator system (WSDI), which contains 6 first-level indicators and 16 second- level indicators. Then we adopt the entropy method to establish concepts of Supply Index (SI) and Demand Index (DI). Next, we transform the traditional GE-Matrix by generalizing the axes as SI vs. DI and dividing it into five diagonal-parallel areas. Then, we choose Qingdao in our following analysis. Based on the WSDI model, we construct the Autoregressive Integrated Moving Average (ARIMA) model to forecast water situation in Qingdao.
\end{abstract}

\section{Introduction}

Water scarcity is the lack of sufficient available water resources to meet water needs within a region. It affects every continent and around 2.8 billion people around the world at least one month out of every year. More than 1.2 billion people lack access to clean drinking water [1] [2].

Humans require water resources for industrial, agricultural, household, and environmental needs. And the water supply not only constrained by total water resources of a region, but also the water management.

\section{Water Supply and Demand Indicators (WSDI) System}

With the purpose of giving a full-scale evaluation of a region's water supply and demand, a series of indicators is used, namely Water Supply and Demand Indicator (WSDI). Since there is no global consensus of how WSDI should be selected, we therefore choose the indexes based on three principals:

- The indicators should be as comprehensive as possible to include most parts which are effective to evaluate water supply and/or demand.

- The indicators which have already been tested reasonable in existent researched have a priority. Based on these principles, respectively for water supply and demand, we construct indicators in 2 levels, shown in Table 1.

Table 1 Systems of indicators for water supply and water demand

\begin{tabular}{|c|c|c|}
\hline & Level 1 & Level 2 \\
\hline \multirow{11}{*}{ Water demand } & \multirow{5}{*}{ Agricultural needs } & Annual precipitation \\
\hline & & Annual average temperature \\
\hline & & Evapotranspiration \\
\hline & & Sown area \\
\hline & & Agricultural production \\
\hline & Industrial needs & Industrial production \\
\hline & \multirow{4}{*}{ Household needs } & Urban population \\
\hline & & Rural population \\
\hline & & Urban income \\
\hline & & Rural income \\
\hline & environmental needs & Green area \\
\hline Water supply & Total water resources & $\begin{array}{l}\text { Surface water } \\
\text { Ground water }\end{array}$ \\
\hline
\end{tabular}




\section{A Measurement of Water Supply and Demand}

In this section, the Entropy Method is adopted to determine weight of WSDI. Then we calculate comprehensive performances on supply and demand. Consequently, we define Supply Index (SI) and Demand Index (DI) to describe the water resources of a region.

\section{The Entropy Method[3]}

By adopting the Entropy Method, we can process the data into two main variables (for water supply), representing total water resources, water management; and four main variables (for water demand), representing industrial, agricultural, household, and environmental needs.

Using the entropy method to determine weight basically has the following three steps [3]:

Step1---Normalization of the original evaluating matrix

Suppose there are evaluating indicators counted $m$, evaluating objects counted $n$, then forms an original indicators value matrix $A=\left(a_{i j}\right)_{m \times n}$. Among these indicators, to which the bigger the better, there are

$$
r_{i j}=\frac{a_{i j}-\min _{j}\left\{a_{i j}\right\}}{\max _{j}\left\{a_{i j}\right\}-\min _{j}\left\{a_{i j}\right\}},
$$

to which the smaller the better, there are

$$
r_{i j}=\frac{\max _{j}\left\{a_{i j}\right\}-a_{i j}}{\max _{j}\left\{a_{i j}\right\}-\min _{j}\left\{a_{i j}\right\}} .
$$

In this paper, we divide the second level indicators into two groups. And only the annual precipitation is the smaller the better.

Step2---Definition of the entropy

The entropy of $i$ th indicator is defined as

$$
H_{i}=-k \sum_{j=1}^{n} f_{i j} \ln f_{i j}, \quad i=1,2, \cdots, m
$$

In which $f_{i j}=r_{i j} / \sum_{j=1}^{n} r_{i j}, k=1 / \ln n$, and suppose when $f_{i j}=0, f_{i j} \ln f_{i j}=0$.

Step3---Definition of the weight of entropy

The weight of entropy of $i$ th indicator can be defined as:

$$
w_{i}=\frac{1-H_{i}}{m-\sum_{i=1}^{m} H_{i}},
$$

in which $0 \leq w_{i} \leq 1, \sum_{i=1}^{m} w_{i}=1$.

Hence, the comprehensive performance of sample $j$ by considering indicators 1 to $n$ can be defined as

$$
F=\sum_{i=1}^{n} w_{i} \cdot f_{i j}
$$

Thus, the value of all the first-level indicators can be calculated by equitation (5).

Furthermore, we use a Supply Index (SI) to depict a region's water supply ability and Demand Index (DI) to depict a region's water demand. Descriptions are shown in Equation (6) as follows: 


$$
S I=\sum_{i=1}^{n_{S I}} w_{i(S I)} \cdot f_{i j(S I)}, \quad i=1,2, \ldots, n_{S I} \quad D I=\sum_{i=1}^{n_{D I}} w_{i(D I)} \cdot f_{i j(D I)}, \quad i=1,2, \ldots, n_{D I}
$$

\section{The "GE-Matrix"[4] for Water Supply and Demand}

Here we consider transforming the GE-Matrix to vividly depict water supply and demand. Like the GE-Matrix, we devise a two-dimensional frame and generalize the axes as "Supply Index (SI)" and "the Demand Index (DI)". But unlike the traditional GE-Matrix, as shown in Figure 1, the "GE-Matrix "for Water Supply and Demand has five diagonal-parallel areas which leads to a more lively and accurate conclusions. Each area represents a situation of water supply and demand as shown in Table 2. The area divided according to research by Li, Zhang, and Song [5].

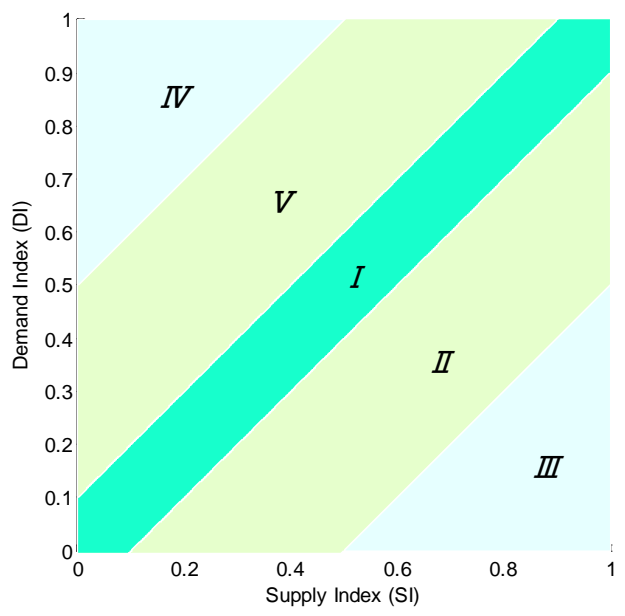

Figure 1 The "GE-Matrix "for Water Supply and Demand

Table 2 The water supply and demand level in different area of the "GE-Matrix"

\begin{tabular}{cccc}
\hline Area & the water supply and demand level & Area & the water supply and demand level \\
\hline I & balance & V & demand exceeds supply slightly \\
II & supply exceeds demand slightly & IV & demand exceeds supply greatly \\
III & supply exceeds demand greatly & & \\
\hline
\end{tabular}

\section{Forecast the Water Situation}

Qingdao is a city in eastern Shandong Province on the east coast of Chinese as well as the largest city in Shandong province. We choose Qingdao as the subject to further study for several reasons:

- The UN water scarcity map indicates that water is heavily overloaded in Qingdao city.

- A complete data set was available for Qingdao, which allowing for an accurate calculation.

In this section, we extend our Water Supply and Demand model by adding the function of forecast. All the 16 second- level indicators we study can be divided into two categories while forecasting: stable indicators which basically not change year by year, mutative indicators which will change year by year. We suppose that there is no significant changes happen to alter the stable indicators during the forecast period, such as political unrest and seasonal epidemic.

For the stable indicators, we use the mean value of eight years data in our forecast. For the mutative indicators, we apply the Autoregressive Integrated Moving Average (ARIMA) model [6]. The reason why we invoke ARIMA model is the indicators we consider are most no stationary time series data. In addition, most of them are seasonal data such as added value of agriculture, which invalidate ARIMA model. Consequently, ARIMA model turns out the best choice for forecast.

Then we use the WSD model to obtain Supply Index (SI) and Demand Index (DI) in 15 years. Figure 2 shows the forecast result of first-level indicators in 15years. We depict the change track of both indexes on our "GE-Matrix", which vividly shows the dynamic change of Qingdao's Water Supply and Demand level (Figure 3). 


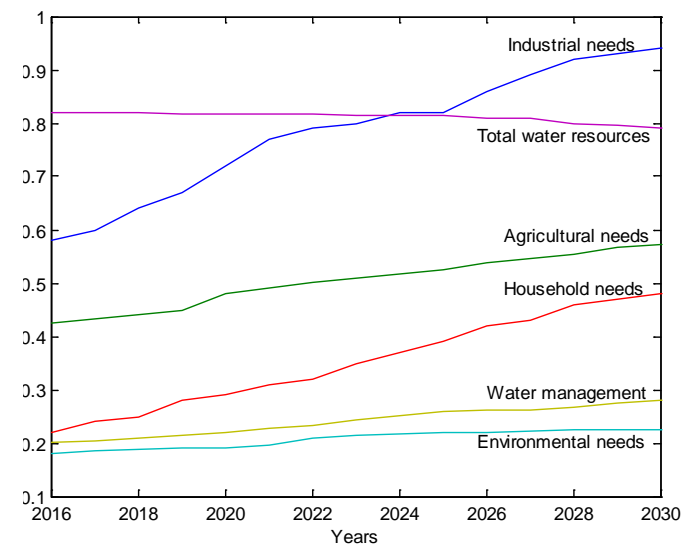

Figure 2 the forecast result of first-level indicators in 15years

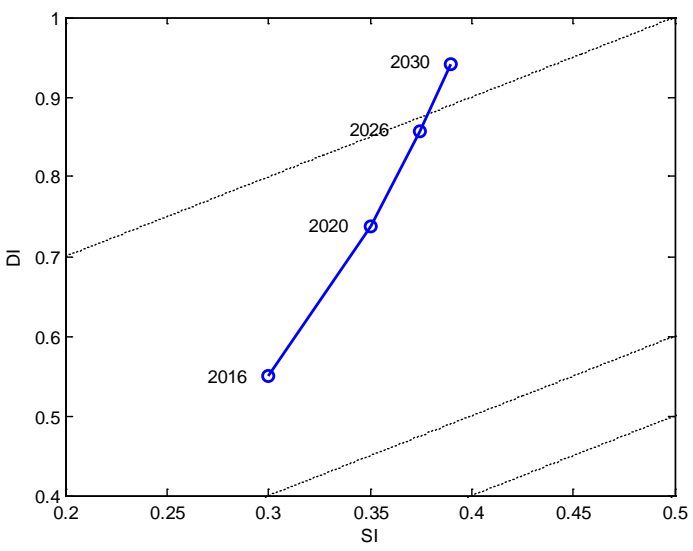

Figure 3 The dynamic change of Qingdao's Water Supply and Demand level

From Figure 2 and Figure 3, we can see in the following 15years:

- $\quad$ total water resources, water management are almost unchanged;

- agricultural, household, and environmental needs rise slowly while industrial needs rises faster;

- $\quad$ water demand exceeds the supply more seriously year by year.

\section{Conclusions}

First, we set up a Water Supply and Demand Indicator system, which contains 6 first-level indicators and 16 second- level indicators. Then we adopt the entropy method to establish concepts of Supply Index (SI) and Demand Index (DI). Next, we transform the traditional GE-Matrix by generalizing the axes as SI vs. DI and dividing it into five diagonal-parallel areas.

Then, we choose Qingdao in our following analysis. Based on the WSD model, we construct the Autoregressive Integrated Moving Average (ARIMA) model to forecast water situation. This model shows that for Qingdao, water demand exceeds the supply more seriously year by year.

\section{References}

[1] World Health Organization. (2005). International decade for action Water For Life, 2005-2015. Relevé épidémiologique hebdomadaire/Section d'hygiène du Secrétariat de la Société des Nations $=$ Weekly epidemiological record/Health Section of the Secretariat of the League of Nations, 80(22), 195.

[2] Wikipedia. Physical water scarcity [online]. Available from: https : // en. wikipedia. Org /wiki / Physical_water_scarcity. [Accessed on $29^{\text {th }}$ January, 2016].

[3] Zou, Z. H., Yi, Y., \& Sun, J. N. (2006). Entropy method for determination of weight of evaluating indicators in fuzzy synthetic evaluation for water quality assessment. Journal of Environmental Sciences, 18(5), 1020-1023.

[4] Wikipedia. G.E. multi factoral analysis [online]. Available from: https:/ /en. Wikipedia .org/ wiki/ G ._E._multi _ factoral_analysis. [Accessed on $30^{\text {th }}$ January, 2016]

[5] Li, Y., Zhang, K. S., Song, N., Chen, L. (2012).Comparison of Two Analytical Approaches in the Assessment of Urban Sustainable Development. Huanjing Kexue yu Jishu, 35(8),1991C205.

[6] Box J, Jenkins G M. Reinsel. Times Series Analysis, Forecasting and Control [J].1994. 